\title{
Alterations of autonomic nervous activity in recurrence of variant angina
}

M Takusagawa, S Komori, K Umetani, T Ishihara, T Sawanobori, I Kohno, S Sano, D Yin, H Ijiri, K Tamura

\begin{abstract}
Objective-To investigate whether autonomic nervous activity is involved in the recurrence of spontaneous coronary spasm in variant angina.

Design-Retrospective analysis.

Setting-Cardiology department of a university hospital.

Patients-18 patients with variant angina were divided into single attack group (SA; nine patients) and multiple attack group (MA; nine patients) according to the frequency of ischaemic episodes with ST segment elevation during 24 hour Holter monitoring.

Methods-Heart rate variability indices were calculated using MemCalc method, which is a combination of the maximum entropy method for spectral analysis and the non-linear least squares method for fitting analysis, at $\mathbf{3 0}$ second intervals for 30 second periods, from 40 minutes before the attack to 30 minutes after the attack. High frequency (HF; 0.04-0.15 Hz) was defined as a marker of parasympathetic activity, and the ratio of low frequency (LF; $0.15-0.40 \mathrm{~Hz}$ ) to high frequency (LF/HF) as an indicator of sympathetic activity. The averaged value during the 40 to 30 minute period before an attack was defined as the baseline.
\end{abstract}

Results-Compared with baseline, the HF component decreased in both groups at two minutes before the attack $(p<0.01)$, and the LF/HF ratio decreased at three minutes before the attack $(p<0.01)$. The baseline LF/HF was lower in the MA group than in the SA group $(p<0.01)$.

Conclusions-A reduction of sympathetic activity may play a key role in determining the recurrence of transient ischaemic events caused by spontaneous coronary spasm in patients with variant angina. (Heart 1999;82:75-81)

Keywords: sympathetic activity; recurrence of coronary spasm; MemCalc method; variant angina

Variant angina pectoris, defined by Prinzmetal et $a l,{ }^{1}$ is characterised by repeated attacks at rest, accompanied by ST segment elevation on the ECG. It is also well known that spasm of the coronary arteries plays an important role in the pathophysiology of variant angina. ${ }^{23} \mathrm{Al}-$ though the precise mechanism of coronary spasm is unclear, we and others have reported that either sympathetic or parasympathetic stimulation can induce coronary spasm. ${ }^{4-7}$
Recently, heart rate variability analysis has been used to evaluate autonomic nervous activity, ${ }^{8-10}$ and there are studies reporting the relation between coronary spasm and autonomic activity. ${ }^{11}{ }^{12}$ In addition, it has been observed that some patients with variant angina have frequent attacks while others do not; from this it has been deduced that there is recurrent coronary spasm caused by sympathetic or parasympathetic nervous activity, though this has not yet been demonstrated. Thus an examination of the variation in autonomic nervous activity might improve our understanding of the mechanism of these attacks.

Most previous studies have used spectral techniques based on the fast Fourier transform (FFT). However, FFT is insufficient to estimate the precise power spectral density from short time series data. The MemCalc method $^{13-16}$ is a new technique for time series analysis, which is a combination of the maximum entropy method (MEM) for spectral analysis and the non-linear least squares method (LSM) for fitting analysis. This enabled us to achieve a reliable analysis of the low frequency component (LF; $0.15-0.40 \mathrm{~Hz}$ ) over a minimum interval of 30 seconds.

Our study was designed to investigate whether variation in autonomic nervous system activity is involved in the recurrence of coronary spasm in patients with variant angina by analysing heart rate variability using the MemCalc method.

\section{Methods}

STUDY PATIENTS

Our study included 18 untreated patients with variant angina (17 male, one female; mean (SD) age 60.5 (7.0) years) who attended the outpatient department complaining of chest pain sustained for at least several minutes at rest, and who were admitted for evaluation. Patients with myocardial infarction, organic heart disease such as cardiomyopathy, or valvar heart disease, congestive heart failure, diabetes mellitus, renal dysfunction, and arterial fibrillation were excluded from the study. All drugs except for sublingual glyceryl trinitrate were stopped for at least three days, as was smoking, after which all patients underwent a 24 hour Holter recording. Each patient with variant angina had resting angina associated with ST segment elevation of $\geqslant 1 \mathrm{~mm}$ on the Holter ECG during the night rest period.

Of the 18 patients studied, nine had only one ischaemic episode with ST segment elevation during the 24 hour Holter recording (number 
of analysed ischaemic episodes $=9$ ); these were defined as the single attack (SA) group. The remaining nine patients had two or more attacks in the same period (number of analysed ischaemic episodes $=29$ ) and were defined as the multiple attack (MA) group.

To assess whether heart rate variability indices were affected by the site of coronary spasm, we divided the patients into subgroups, as follows. Of the 13 patients in whom ST segment elevation was recognised in modified lead II of the Holter ECG, and coronary spasm was observed in the right coronary artery on provocation by intracoronary ergonovine or acetylcholine, seven were in the SA group (number of analysed episodes $=7$ ) and six were in the MA group (number of analysed episodes $=22$ ). Only five patients had left coronary artery spasm, too small a number for further analysis.

After Holter monitoring, coronary angiography was performed in all patients by the Judkin technique. Coronary spasm was induced by intracoronary administration of ergonovine (up to $40 \mu \mathrm{g}$ ) or acetylcholine (up to $100 \mu \mathrm{g}$ ). We then gave $2 \mathrm{mg}$ of isosorbide nitrate into each coronary artery and performed coronary angiography again. In no patient was there a significant organic stenosis (more than 50\% reduction in lumen diameter). In all 13 patients in whom ST segment elevation was observed in modified lead II, coronary spasm was induced in the right coronary artery. Echocardiography was done in all patients, but there was no evidence of abnormality of cardiac function, and no cardiac hypertrophy or dilatation of the cardiac chambers were observed.

PROCESSING THE 24 HOUR HOLTER RECORDING The Holter ECG was recorded using two channel tape recorder during a 24 hour period in all patients (Del Mar Avionics, model 456A; Strata Scan, Los Angeles, California, USA). We used lead CM5 and modified lead II for the two channels. All patients were asked to keep a detailed diary of their activities during the 24 hour monitoring period, including the time they went to bed, the time they woke up, and symptoms such as chest pain. The tapes were analysed by two expert cardiologists with the Del Mar Avionics analyser (model 563). When ST segment elevation was $1 \mathrm{~mm}(0.1 \mathrm{mV})$ or more at $80 \mathrm{~ms}$ after the J point from the baseline ST segment position and lasted for one minute or more in consecutive beats, we defined the episodes as significant ST segment elevation regardless of chest pain. We defined the onset of a vasospastic angina attack as an ST segment elevation of $0.5 \mathrm{~mm}(0.05 \mathrm{mV})$ at $80 \mathrm{~ms}$ after the J point. We recorded the number of attacks, the degree of ST segment elevation at the onset of the attacks, and the duration of the ischaemic episodes for each Holter recording.

HEART RATE VARIABILITY ANALYSIS

An ischaemic episode with ST segment elevation was considered significant if it was separated from both a previous episode and a subsequent attack by at least one hour. In this case the ischaemic episode was selected for analysis. We excluded patients with excessive artefacts, significant arrhythmia, bundle branch block, and marked repolarisation abnormalities that might cause alterations in the results of the heart rate variability analysis.

Time domain analysis and spectral analyses of heart rate variability using the MemCalc system $^{13-16}$ (MemCalc Version 2.5, Suwa Trust Co, Tokyo, Japan) were performed for each 30 second period at 30 second intervals starting from 40 minutes before the attack and continuing until 30 minutes after the attack. We obtained the RR interval (ms) as the time domain index of heart rate variability. The ECG recordings were played back from the two channel tape recorder and the signals were digitised using a 12 bit analogue to digital converter at a sampling rate of $1 \mathrm{kHz}$. The signals were analysed using the MemCalc system. During this process ectopic beats were recognised, and then normal to normal (NN) data were identified by excluding the preceding and succeeding $R R$ interval contiguous to the ectopic beats. At least $80 \%$ of RR intervals in a 30 second segment were required to be normal, otherwise the segment was excluded from the overall analysis. Fortunately no segment had to be excluded. Thus we were able to select adequate NN intervals capable of providing sufficiently reliable information for assessing both the low frequency components (LF; $0.04-0.15 \mathrm{~Hz}$ ) and the high frequency components (HF; $0.15-0.40 \mathrm{~Hz}$ ) obtained from the power spectral analysis. ${ }^{17}$ The HF component has been used to infer parasympathetic nervous activity. ${ }^{18} 19$ Because the LF component has typically been related to a combination of parasympathetic and sympathetic influences, ${ }^{9}{ }^{20} 21$ investigators frequently infer sympathetic nervous activity from the $\mathrm{LF} / \mathrm{HF}$ ratio, ${ }^{21-24}$ so that parasympathetic power to some extent cancels out of the ratio, leaving a better indicator of sympathetic activity. The $\mathrm{LF}, \mathrm{HF}$, and $\mathrm{LF} / \mathrm{HF}$ measures are reported as their natural logarithms (Ln).

\section{STATISTICAL ANALYSIS}

The Fisher exact probability test and unpaired $t$ test were used to compare categorical and continuous variables between the two groups, respectively. Because the distribution of the frequency domain measurements of heart rate variability was extremely skewed, a natural logarithm transformation (Ln) of each measure, which produces nearly normal distributions, was applied before statistical analysis was performed. The averaged heart rate variability indices measured during the 40 to 30 minute period before an attack in each group was considered to be the baseline. We examined the time course of each measured variable using analysis of variance (ANOVA) for repeated measures and the $\mathrm{F}$ test. Post hoc comparisons were performed using the Student $t$ test with Bonferroni correction for multiple comparisons. The statistical significance of the differences between two groups at corresponding times was determined by the unpaired $t$ test. All values are represented as mean (SD). A 
Table 1 Patient characteristics

\begin{tabular}{lll}
\hline & $\begin{array}{l}\text { Single attack } \\
\text { group }(n=9)\end{array}$ & $\begin{array}{l}\text { Multiple attack } \\
\text { group }(n=9)\end{array}$ \\
\hline Age (years) & $59.1(7.4)$ & $61.9(6.7)$ \\
Male/female & $9 / 0$ & $8 / 1$ \\
Height (cm) & $161.2(5.2)$ & $161.6(5.3)$ \\
Weight (kg) & $57.4(8.3)$ & $56.9(7.6)$ \\
Systolic BP (mm Hg) & $126(6)$ & $125(9)$ \\
Diastolic BP (mm Hg) & $77(8)$ & $75(5)$ \\
Heart rate (beats/min) & $68(7)$ & $64(5)$ \\
Echocardiography & & \\
$\quad$ IST (mm) & $9.3(0.9)$ & $9.7(1.0)$ \\
PWT (mm) & $9.3(0.9)$ & $9.8(0.8)$ \\
$\quad$ LVEF (\%) & $65(7)$ & $68(8)$ \\
Sleep (hours) & $8.1(0.3)$ & $8.1(0.5)$ \\
\end{tabular}

Values are mean (SD). BP, blood pressure; IST, interventricular septal thickness; LVEF, left ventricular ejection fraction; PWT, left ventricular posterobasal free wall thickness.

probability $(\mathrm{p})$ value of $<0.05$ was regarded statistically significant.

\section{Results}

CLINICAL CHARACTERISTICS

The characteristics of the study population are summarised in table 1 . There were no significant differences in clinical profiles and echocardiographic findings between the two groups. Tables 2 summarises the clinical, Holter monitoring, and angiographic characteristics. Overall, 56 episodes of ischaemic ST segment elevation were observed while recording
24 hour Holter ECGs. We excluded 18 ischaemic episodes in which other attacks were observed within one hour before or after the ischaemic episode. We therefore analysed and examined 38 episodes (average of $3.2(0.8)$ episodes/patient in the MA group). The ischaemic episodes continued for 3.6 (1.1) minutes (range 2.0 to 5.0 minutes) and the ST segment elevation was $3.3(1.0) \mathrm{mm}$ (range 2.0 to $5.0 \mathrm{~mm}$ ).

\section{COMPARISON OF HEART RATE VARIABILITY} INDICES

Table 3 shows the serial data of heart rate variability indices in the SA and MA groups. The data are shown in fig 1 .

Figure 1A shows the changes in RR interval in the two groups. The averaged RR interval (averaged interval from 40 minutes before to 30 minutes after an attack) in the MA group was significantly longer than in the SA group (1043 (83) v 901 (117) ms, $\mathrm{p}<0.01)$. There was no significant variation until 0.5 minutes before an attack in the MA group, and until one minute before an attack in the SA group. However, the RR interval in the MA group was decreased at the time of the attack compared with baseline $(\mathrm{p}<0.01)$, and then gradually returned to baseline. In the SA group, the RR interval was reduced at one minute before an

Table 2 Clinical, Holter monitoring, and angiographic characteristics of patients with variant angina

\begin{tabular}{|c|c|c|c|c|c|c|}
\hline \multirow[b]{2}{*}{ Patient } & \multirow[b]{2}{*}{ Age/sex } & \multicolumn{2}{|c|}{ Holter monitoring } & \multicolumn{3}{|l|}{ Angiography } \\
\hline & & $\begin{array}{l}\text { Episodes } \\
\text { analysed (n) }\end{array}$ & $\begin{array}{l}\text { Lead with } S T \\
\text { segment elevation }\end{array}$ & Control & Stimulus & During spasm \\
\hline 1 & $61 / M$ & 1 & Modified II & Normal & Ergo & RCA $100 \%$ \\
\hline 2 & $56 / \mathrm{M}$ & 1 & Modified II & Normal & Ach & RCA $100 \%$ \\
\hline 3 & $54 / \mathrm{M}$ & 1 & Modified II & Normal & Ach & RCA $100 \%$ \\
\hline 4 & $62 / \mathrm{M}$ & 1 & Modified II & Normal & Ach & RCA $100 \%$ \\
\hline 5 & $64 / \mathrm{M}$ & 1 & CM5 & Normal & Ach & LCX $99 \%$ \\
\hline 6 & $58 / M$ & 1 & Modified II & Normal & Ach & RCA $100 \%$ \\
\hline 7 & $72 / \mathrm{M}$ & 1 & CM5 & Normal & Ach & LAD $100 \%$ \\
\hline 8 & $45 / \mathrm{M}$ & 1 & Modified II & RCA $25 \%$ stenosis & Ergo & RCA $100 \%$ \\
\hline 9 & $60 / M$ & 1 & Modified II & Normal & Ach & RCA $100 \%$ \\
\hline 10 & $71 / \mathrm{M}$ & 2 & CM5 & Normal & Ach & LAD $99 \% / L C X 90 \%$ \\
\hline 11 & $55 / \mathrm{F}$ & 3 & Modified II & Normal & Ach & RCA $100 \%$ \\
\hline 12 & $62 / \mathrm{M}$ & 2 & CM5 & Normal & Ach & LAD $90 \% / L C X 90 \%$ \\
\hline 13 & $55 / \mathrm{M}$ & 4 & Modified II & Normal & Ach & RCA $100 \%$ \\
\hline 14 & $61 / M$ & 3 & Modified II & RCA $25 \%$ stenosis & Ach & RCA $100 \%$ \\
\hline 15 & $53 / \mathrm{M}$ & 4 & Modified II & Normal & Ach & RCA $100 \%$ \\
\hline 16 & $62 / \mathrm{M}$ & 4 & Modified II & Normal & Ach & RCA $100 \%$ \\
\hline 17 & $68 / \mathrm{M}$ & 3 & CM5 & Normal & Ach & \\
\hline 18 & $70 / \mathrm{M}$ & 4 & Modified II & Normal & Ach & RCA $100 \%$ \\
\hline
\end{tabular}

Ach, acetylcholine; Ergo, ergonovine; LAD, left anterior descending coronary artery; LCX, left circumflex coronary artery; RCA, right coronary artery.

Table 3 Changes in heart rate variability indices in single attack (SA) and multiple attack (MA) groups before, during, and after angina attacks with ST segment elevation

\begin{tabular}{|c|c|c|c|c|c|c|c|}
\hline & \multirow[b]{2}{*}{ Baseline } & \multicolumn{4}{|l|}{ Before (min) } & \multirow[b]{2}{*}{ Onset } & \multirow{2}{*}{$\begin{array}{l}\text { After (min) } \\
5\end{array}$} \\
\hline & & 5 & 3 & 2 & 1 & & \\
\hline \multicolumn{8}{|c|}{$\mathrm{RR}$ interval (ms) } \\
\hline SA & $924(106) \dagger$ & $896(110) \dagger$ & $864(116) \dagger$ & $859(134) \dagger$ & 753 (59)S† & $821(125) \dagger$ & $880(179) \dagger$ \\
\hline MA & $1058(84)$ & $1064(107)$ & $1060(119)$ & $1060(120)$ & $1048(116)$ & $995(112) \S$ & $1021(130)$ \\
\hline \multicolumn{8}{|c|}{$\operatorname{LnLF}\left(\mathrm{ms}^{2}\right)$} \\
\hline SA & $6.96(0.48) \dagger$ & $6.77(0.77)$ & $5.42(0.39) \ddagger$ & $6.41(0.33)$ & $7.61(0.64) \dagger$ & $9.07(0.34) \S \dagger$ & $6.87(0.96)$ \\
\hline MA & $6.09(0.76)$ & $6.12(1.20)$ & $5.65(0.65) \S$ & $6.11(0.68)$ & $6.58(0.98)$ & $7.54(0.75) \S$ & $6.43(0.70)$ \\
\hline \multicolumn{8}{|c|}{$\operatorname{LnHF}\left(\mathrm{ms}^{2}\right)$} \\
\hline SA & $5.42(0.48)$ & $5.24(0.47)$ & $5.08(0.27)^{\star}$ & $4.67(0.27) \ddagger$ & $5.71(0.69)$ & $7.11(0.30) \mathrm{S} \dagger$ & $5.55(0.65)$ \\
\hline MA & $5.40(0.83)$ & $5.46(0.83)$ & $5.54(0.57)$ & $4.92(0.59) \ddagger$ & $5.26(0.90)$ & $6.52(0.37) \oint$ & $5.69(0.68)$ \\
\hline \multicolumn{8}{|c|}{$\mathrm{LnLF} / \mathrm{HF}$} \\
\hline SA & $1.54(0.15) \dagger$ & $1.53(0.37) \dagger$ & $0.34(0.23) \S$ & $1.74(0.23) \S \dagger$ & $1.90(0.16) \S t$ & $1.96(0.14) \S \dagger$ & $1.32(0.84) \dagger$ \\
\hline MA & $0.68(0.25)$ & $0.67(0.68)$ & $0.11(0.35) \int$ & $1.19(0.33) \int$ & $1.32(0.27) \sqrt{ }$ & $1.02(0.72)$ & $0.74(0.41)$ \\
\hline
\end{tabular}

Values are mean (SD). Number of ischaemic episodes analysed in SA group (9 patients) was 9, and in MA group (9 patients) was 29 . Baseline averaged RR interval, averaged $\mathrm{LnLF}$, averaged $\mathrm{LnHF}$, and averaged $\mathrm{LnLF} / \mathrm{HF}$ during the 40 to $30 \mathrm{~min}$ period before attacks.

${ }^{\star} \mathrm{p}<0.05 v$ MA group; $\mathrm{tp}<0.01 v$ MA group; $\neq \mathrm{p}<0.05 v$ baseline; $\mathrm{Sp}<0.01 v$ baseline. 

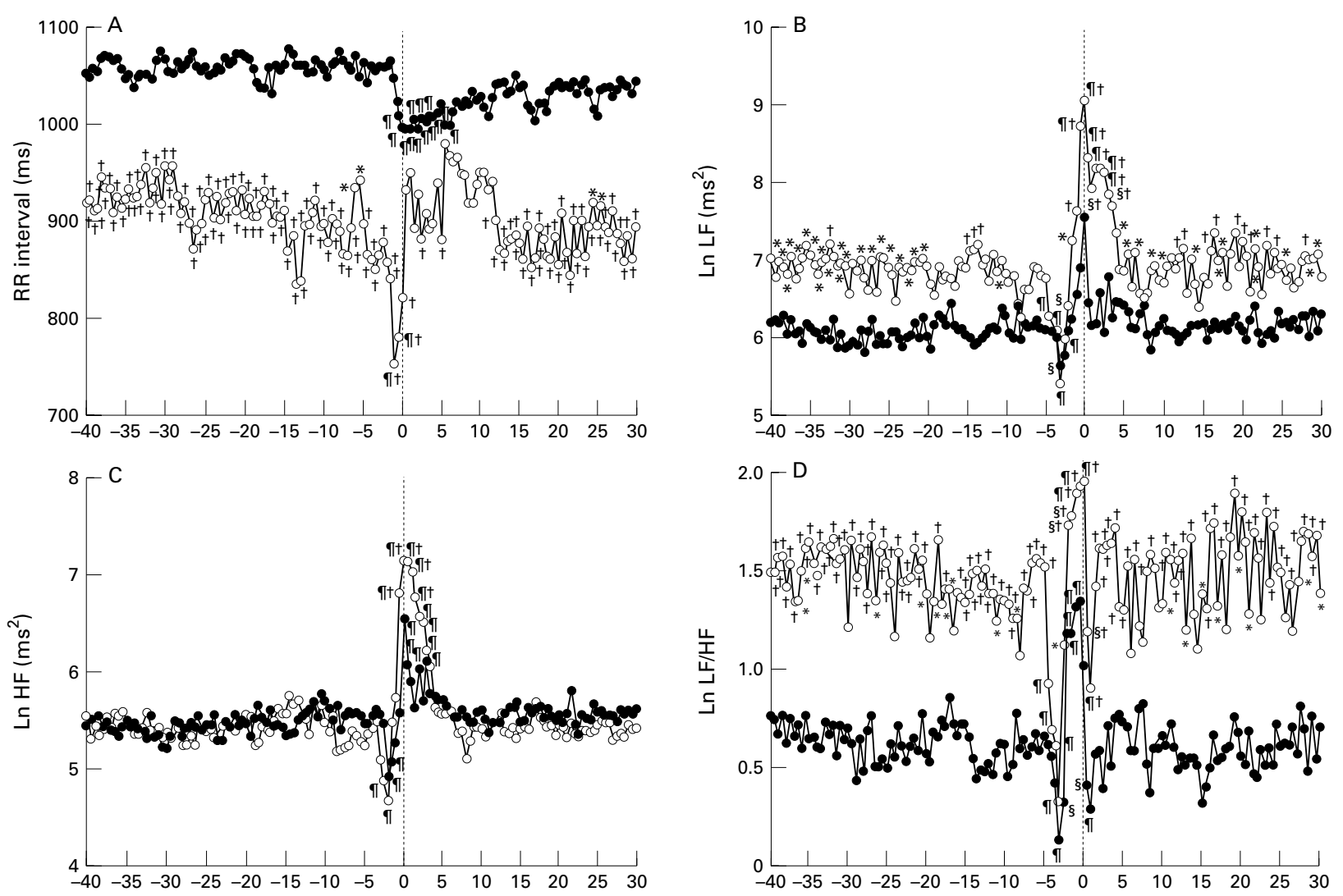

Time $(\min )$

Figure 1 Graphs showing RR interval $(A), L F(B), H F(C)$ and $L F / H F$ ratio (D) in the single attack $(S A)$ group (O) and the multiple attack (MA) group (•) from 40 minutes before an attack to 30 minutes after an attack. For clarity, SD bars are not shown. Baseline $=$ averaged value during the 40 to 30 minute period before an attack. The averaged RR interval in the MA group was significantly higher than in the SA group $(p<0.01)$. In both groups, $H F$ significantly decreased compared with baseline at two minutes before an attack, while $L F$ and $L F / H F$ were significantly reduced compared with baseline at three minutes before an attack. For $L F$ and $L F / H F$, the $M A$ group showed significantly lower values than the $S A$ group before and after the attack $\left(p<0.01\right.$, respectively). ${ }^{*} p<0.05 v M A$ group; $\dagger p<0.01 v M A$ group; $\$ p<0.05 v$ baseline; $₫ p<0.01 v$ baseline. LF, low frequency component (0.04-0.15 Hz); HF, high frequency component $(0.15-0.40 \mathrm{~Hz})$.

attack compared with baseline $(\mathrm{p}<0.01)$, and then returned to the baseline immediately after the attack.

Panels B, C, and D in fig 1 show, respectively, the changes in $\mathrm{LF}, \mathrm{HF}$, and $\mathrm{LF} / \mathrm{HF}$ ratio in the two groups. The averaged LF (averaged value from 40 minutes before to 30 minutes after an attack) was higher in the SA group than in the MA group, at $6.98(0.55)$ v $6.14(0.86) \mathrm{ms}^{2}, \mathrm{p}<0.01$. The LF component in both groups decreased at three minutes before the onset of ischaemia compared with baseline $(p<0.01)$, and then significantly increased at the onset of ischaemia $(p<0.01)$. $\mathrm{HF}$ levels were similar in both groups during the 40 minute to 0.5 minute period before an attack and in the 1.5 to 30 minute period after an attack. At the onset of an attack, the HF component in the SA group was higher than in the MA group ( $<<0.01)$. In both groups, the $\mathrm{HF}$ component was significantly reduced at two minutes preceding the onset of ischaemia

Table 4 Changes in heart rate variability indices in single attack (SA) and multiple attack (MA) groups before, during, and after angina attacks with ST segment elevation in modified lead II of the Holter ECG

\begin{tabular}{|c|c|c|c|c|c|c|c|}
\hline & \multirow[b]{2}{*}{ Baseline } & \multicolumn{4}{|l|}{ Before (min) } & \multirow[b]{2}{*}{ Onset } & \multirow{2}{*}{$\frac{\text { After (min) }}{5}$} \\
\hline & & 5 & 3 & 2 & 1 & & \\
\hline \multicolumn{8}{|c|}{$\mathrm{RR}$ interval (ms) } \\
\hline SA & $907(115) \dagger$ & $876(113) \dagger$ & $855(131) \dagger$ & $843(150) \dagger$ & $753(67)+s$ & $821(141) \dagger$ & $840(153) \dagger$ \\
\hline MA & $1063(90)$ & $1063(120)$ & $1065(127)$ & $1068(124)$ & 1055 (125) & $1002(125) \rrbracket$ & $1020(140)$ \\
\hline \multicolumn{8}{|c|}{$\operatorname{LnLF}\left(\mathrm{ms}^{2}\right)$} \\
\hline SA & $6.99(0.45) \dagger$ & $6.58(0.62)$ & $5.29(0.33) \S$ & $6.34(0.33) \ddagger$ & $7.63(0.73)+\$$ & $9.14(0.35)+\$$ & $7.23(0.59) \dagger$ \\
\hline MA & $6.10(0.80)$ & $6.00(1.23)$ & $5.51(0.60) \S$ & $6.11(0.64)$ & $6.57(0.75)$ & $7.61(0.73) \Phi$ & $6.39(0.63)$ \\
\hline \multicolumn{8}{|c|}{$\operatorname{LnHF}\left(\mathrm{ms}^{2}\right)$} \\
\hline SA & $5.40(0.49)$ & $5.07(0.33)$ & $5.01(0.25)$ & $4.61(0.28) \S$ & $5.69(0.78)$ & $7.15(0.33) \mathbb{S} \dagger$ & $5.68(0.69)$ \\
\hline MA & $5.39(0.81)$ & $5.37(0.87)$ & $5.40(0.56)$ & $4.93(0.59) \oint$ & $5.20(0.71)$ & $6.54(0.34) \S$ & $5.67(0.57)$ \\
\hline \multicolumn{8}{|c|}{$\mathrm{LnLF} / \mathrm{HF}$} \\
\hline SA & $1.59(0.10) \dagger$ & $1.51(0.34) \dagger$ & $0.27(0.21) \mathbb{S}$ & $1.73(0.24) \dagger \ddagger$ & $1.94(0.15)+\$$ & $1.99(0.13)+\S$ & $1.56(0.72) \dagger$ \\
\hline MA & $0.70(0.16)$ & $0.63(0.61)$ & $0.11(0.30) \S$ & $1.17(0.25) \S$ & $1.38(0.23) \S$ & $1.07(0.74)$ & $0.72(0.46)$ \\
\hline
\end{tabular}

Values are mean (SD). Number of ischaemic episodes analysed in SA group (7 patients) was 7, and in MA group (6 patients) was 22. Baseline $=$ averaged RR interval, averaged LnLF, averaged LnHF, and averaged LnLF/HF during the 40 to 30 min period before attacks.

$\mathrm{tp}<0.01 v$ MA group; $\ddagger \mathrm{p}<0.05 v$ baseline; $\$ \mathrm{p}<0.01 v$ baseline. 

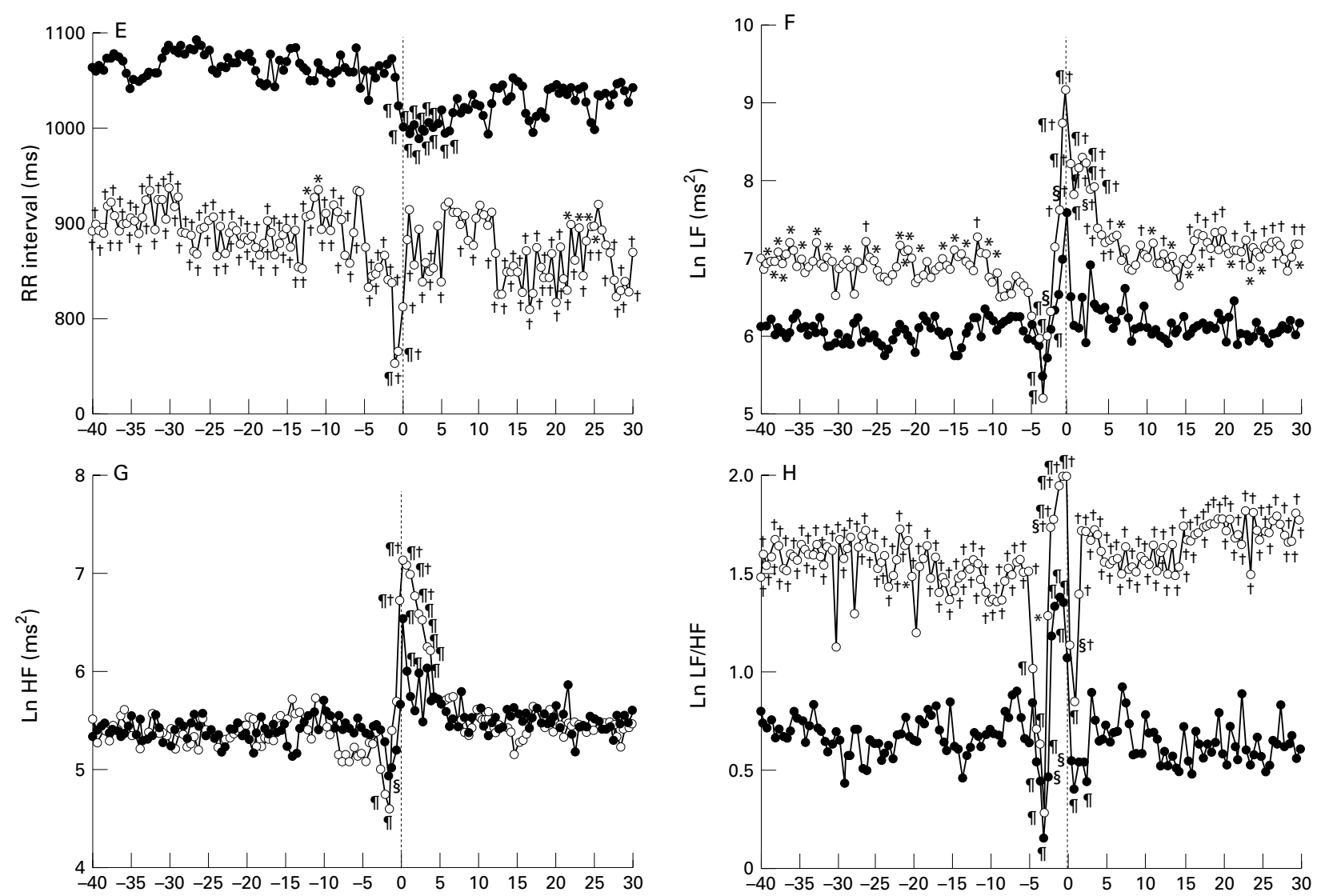

Time $(\min )$

Figure 2 Graphs showing $R R$ interval $(E), L F(F), H F(G)$, and $L F / H F$ ratio $(H)$ in the single attack $(S A)$ group (O) and the multiple attack (MA) group (•) with ST segment elevation in the modified lead II of the Holter ECG from 40 minutes before an attack to 30 minutes after an attack. For clarity, $S D$ bars are not shown. Baseline $=$ averaged value during the 40 to 30 minute period before an attack. The results are similar to those of fig $1 .{ }^{*} p<0.05 \mathrm{v}$ MA group; $\nmid p<0.01$ v MA group; $\$ p<0.05$ v baseline; $\Phi_{p}<0.01$ v baseline. $L F$, low frequency component $(0.04-0.15 \mathrm{~Hz}) ; \mathrm{HF}$, high frequency component $(0.15-0.40 \mathrm{~Hz})$.

compared with baseline $(\mathrm{p}<0.01)$, and then increased at the onset of ischaemia $(\mathrm{p}<0.01)$. The averaged $\mathrm{LF} / \mathrm{HF}$ ratio (averaged from 40 minutes before to 30 minutes after an attack) in the SA group was higher than in the MA group, at $1.52(0.25) v 0.73(0.32), \mathrm{p}<0.01$. The $\mathrm{LF} / \mathrm{HF}$ ratio in both groups fell at three minutes before the onset of ischaemia compared with baseline $(\mathrm{p}<0.01)$, and then became significantly increased at two minutes before ischaemia $(\mathrm{p}<0.01)$.

SUBGROUP ANALYSIS

Table 4 shows the serial data of heart rate variability indices in 13 patients with right coronary spasm. The data are shown in fig 2 .

In these figures, the findings in the subgroups were similar to the results for all subjects.

\section{Discussion}

Our results show that the ischaemic episodes are preceded by a significant reduction in the $\mathrm{LF} / \mathrm{HF}$ ratio, and that the baseline $\mathrm{RR}$ interval and $\mathrm{LF} / \mathrm{HF}$ ratio are lower in patients with multiple daily ischaemic episodes than in patients who have a single ischaemic episode. These observations support the role of sympathetic activity as a contributing factor to the recurrence of transient ischaemic events caused by spontaneous coronary spasm.
ASSESSMENT OF HEART RATE VARIABILITY BY SPECTRAL ANALYSIS

High frequency power represents the vagal function of heart rate caused by the respiratory cycle and the depth of respiration. ${ }^{18}{ }^{19}$ Low frequency power reflects the adjustment of both vagal and sympathetic activities. ${ }^{24}{ }^{25}$ Several previous reports have used the $\mathrm{LF} / \mathrm{HF}$ ratio to measure the sympathovagal balance. ${ }^{918}$ The $\mathrm{LF} / \mathrm{HF}$ ratio may not only provide insight into autonomic balance, but also an estimate of sympathetic activity, providing an estimate of vagal tone is available. Time based frequency domain analysis of heart rate variability has great promise for studying the dynamics of the autonomic nervous system. ${ }^{26}$ In this study, the $\mathrm{HF}$ showed comparable values between the two groups before and after ischaemic episodes at rest in the night periods. We therefore used the $\mathrm{LF} / \mathrm{HF}$ ratio to assess sympathetic activity.

A previous study reported that the $\mathrm{HF}$ component increased during the 10 minute period before ischaemic episodes of nocturnal variant angina, whereas the LF component increased during the five minute period before such episodes ${ }^{11}$; another study reported that although the $\mathrm{HF}$ components transiently and significantly decreased at two minutes before an attack, the LF/HF ratio did not show any significant change. ${ }^{12}$ The special report in 
Circulation $^{27}$ recommends two minute intervals to study the LF component. Thus almost all previous studies have been performed using a minimum interval of two minutes. However, important data may be lost during those two minutes, because autonomic nervous activity changes markedly before and after the onset of ischaemic episodes. In these previous studies, the spectral technique was based on the FFT. However, the FFT has its own drawbacks, such as poor resolution owing to the effect of window functions, and unrealistic assumptions about extending the data. Furthermore, the FFT is insufficient to estimate the precise power spectral density from short time series data.

The present analysis was carried out using the MemCalc method. ${ }^{13-16}$ This method is a new technique for time series analysis, which is a combination of the MEM for spectral analysis and the non-linear LSM for fitting the analysis in the time domain. This new method enabled us to achieve a reliable analysis of the low frequency component (LF, 0.15-0.40 Hz) on a minimum interval of 30 seconds. In our data, the HF showed a significant decrease transiently at two minutes before an attack, and the $\mathrm{LF} / \mathrm{HF}$ ratio significantly fell at three minutes before an attack. This findings imply that the decrease in vagal activity is preceded by a reduction in sympathetic activity. Furthermore, the $\mathrm{LF} / \mathrm{HF}$ ratio in the MA group was always low compared with the SA group. This suggests that a reduction in sympathetic nerve tone before and after the attacks is involved in setting the scene for the recurrent ischaemic episodes. Our results differ from those of previous studies ${ }^{11} 12$ showing that an activation of the sympathetic system or a deactivation of the parasympathetic system appeared to play a role in triggering transient myocardial ischaemia caused by coronary spasm. However, spectral analysis was performed for longer periods (two minutes) using the FFT in those previous studies.

PATHOGENESIS OF CORONARY ARTERY SPASM

After coronary artery spasm became a proven cause of variant angina, various pathogenic hypotheses were suggested to explain the origin of this syndrome. However, the fundamental mechanism of coronary spasm has not yet been clearly shown. ${ }^{28}$ We previously reported that there was regional myocardial sympathetic dysfunction in patients with coronary vasospasm. ${ }^{7}$ Some studies have suggested that activation of sympathetic activity could be the main cause of coronary spasm, ${ }^{29-31}$ but others have denied this hypothesis. ${ }^{32} 33$ On the other hand, because most patients tend to have anginal attacks at rest during the night, ${ }^{34}$ or because of the possibility that cholinergic agents might induce coronary spasm, ${ }^{5637}$ it has been suggested that vagal activity may play a significant role in coronary spasm. However, the concentration of drugs necessary to induce coronary spasm was greater than that generated physiologically in the coronary arteries. Furthermore, angina at night is considered to occur usually during REM sleep, ${ }^{38}$ and some recent studies have reported that sympathetic activity plays a role in triggering ischaemic attacks during REM sleep. ${ }^{39}$ In the present study, it was difficult to determine sleep level because we did not use electroencephalography or polysomnography. However, the fact that most attacks occurred at night and that before an attack significant variations of $\mathrm{LF} / \mathrm{HF}$ ratio were observed, preceding the rapid HF variation in our data, suggests that a change in sympathetic activity triggered the onset of coronary spasm.

\section{EXAMINATION OF THE SUBGROUPS}

Several studies have reported changes in heart rate variability according to whether the left or the right coronary artery was occluded. In one study, heart rate variability analysis during balloon coronary angioplasty was reported in a group with occlusion of the right coronary artery compared with a group with occlusion of the left coronary artery; some cases showed increased heart rate variability and others showed decreased variability, but no significant difference was observed between the two groups. ${ }^{41}$ In another study it was reported that among cases with acute myocardial infarction, heart rate variability was lower in those with anterior infarction than in those with posterior infarction. $^{42}$

To assess whether heart rate variability indices are affected by the site of coronary spasm, we examined the subgroup subjects in the same way. The results for the subgroups were similar to those for all subjects combined, implying that the heart rate variability indices in the present study were not affected by the site of coronary spasm.

\section{STUDY LIMITATIONS}

First, the LF/HF ratio will not provide an accurate measure of sympathetic tone. Vagal activity is the major contributor to the HF component, ${ }^{18} 19$ but there is disagreement with respect to the LF component. It has been suggested $^{8}$ that LF, when expressed in normalised units, is a quantitative marker of sympathetic modulation; alternatively it has been suggested that LF reflects both sympathetic activity and vagal activity. ${ }^{9}$ Consequently, the $\mathrm{LF} / \mathrm{HF}$ ratio is considered by some investigators ${ }^{21-23}$ to reflect sympathetic modulation. We therefore used the $\mathrm{LF} / \mathrm{HF}$ ratio as a better indicator of sympathetic activity. Further accurate non-invasive indices are needed to investigate sympathetic activity.

Second, it would be better to compare "good" days and "bad" days in the same patients with variant angina. However, we had no data in these patients in our present study. If we could examine whether differences in autonomic nervous activity exist in the same patient, the relation between the recurrence of attacks and autonomic nervous activity could be evaluated more accurately.

Third, the number of ischaemic episodes in the single and the multiple attack groups differed in our study, which may have affected the analysis. We therefore randomly extracted single episodes from each multiple attack 
group to match with episodes in the single attack group and compared the two groups by repeating the procedure. The results did not differ from those reported here.

Fourth, the coronary artery spasm may have further preceded the time detected for an ST segment elevation of $0.5 \mathrm{~mm}$, defined as the onset of the angina attack in the present study. However, we could not precisely detect the moment when coronary spasm was induced from the Holter ECG. Thus we could not completely exclude the possibility that the coronary spasm and the autonomic changes were secondary to some unknown mechanism.

CONCLUSIONS

Our study shows that the $\mathrm{HF}$ and the LF/HF ratio transiently decrease immediately before spontaneous coronary spasm; the decrease in $\mathrm{HF}$ is preceded by the reduction in the $\mathrm{LF} / \mathrm{HF}$ ratio, and the baseline $R R$ interval and the $\mathrm{LF} / \mathrm{HF}$ ratio are lower in patients with multiple daily ischaemic episodes than in those who have a single ischaemic episode. These findings suggest that a reduction in sympathetic activity plays a key role in determining the recurrence of transient ischaemic events caused by coronary spasm in patients with variant angina.

1 Prinzmetal M, Kennamer R, Merliss R, et al. A variant form of angina pectoris. Am ₹ Med 1959;27:375-88.

2 Maseri A, Severi S, DeNes M, et al. "Variant angina": one aspect of a continuous spectrum of vasospastic myocardial aspect of a continuous spectrum of vasospast

3 Hillis LD, Braunwald E. Coronary artery spasm. N Engl $\mathcal{f}$ Med 1978;299:695-702.

4 Yasue $\mathrm{H}$, Touyama M, Kato $\mathrm{H}$, et al. Prinzmetal's varian form of angina as a manifestation of alpha-adrenergic receptor mediated coronary artery spasm: documentation by coronary arteriography. Am Heart 7 1976;91:148-55.

5 Yasue H, Horio Y, Nakamura N, et al. Induction of coronary artery spasm by acetylcholine in patients with variant angina: possible role of the parasympathetic nervous system in the pathogenesis of coronary artery spasm. Circulation 1986;74:955-63.

6 Miwa K, Goto M, Lee JD, et al. Supersensitivity of coronary arteries in variant angina to spasm induced by intracoroarteries in variant angina to spasm induced by

7 Takano H, Nakamura T, Satou T, et al. Regional myocardial sympathetic dysinnervation in patients with coronary vasospasm. Am 7 Cardiol 1995; 75:324-9.

8 Akselroid S, Gordon D, Ubel FA, et al. Power spectral analysis of heart rate fluctuations: a quantitative probe of beat cardiovascular control. Science 1981;213:220-3.

9 Malliani A, Pagani M, Lombardi F, et al. Cardiovascular neural regulation explored in the frequency domain. Circulation 1991;84:482-92.

10 Bigger JT. Spectral analysis of R-R variability to evaluate autonomic pharmacology and to predict cardiovascula outcomes in humans. In: Zipes DP, Jalife J, eds. Cardiac electrophysiology: from cell to bedside. Philadelphia: WB Saunders 1994:1151-70

11 Yoshio H, Shimizu M, Sugihara N, et al. Assessment of autonomic nervous activity by heart rate spectral analysis in

12 Lanza GA, Pedrotti P, Pasceri V, et al. Autonomic changes associated with spontaneous coronary spasm in patients associated with spontaneous coronary spasm in patients

13 Sawada Y, Ohtomo N, Tanaka Y, et al. New technique for time series analysis combing the maximum entropy method and non-linear least squares method: its value in method and non-linear least squares method: its value in heart rate variabil

14 Ohtomo N, Tokiwano K, Tanaka Y, et al. Exponential characteristics of power spectral densities caused by chaotic phenomena. F Physiol Soc fpn 1995;64:1104-13.

15 Ohtomo N, Terachi S, Tanaka Y, et al. New method of time series analysis and its application to Wolf's sunspot number data. Jpn f Appl Physiol 1994;33:2821-31.
16 Ohtomo N, Kamo T, Watanabe M, et al. Power spectral densities of temporal variations of blood pressures. $\mathcal{F} p n \mathcal{F}$ Appl Physiol 1996;35:5571-82.

17 Pinna GD, Maestri R, Di Cesare A, et al. The accuracy of power-spectrum analysis of heart-rate variability from annotated RR lists generated by Holter systems. Physiol Meas 1994;15:163-79.

18 Pagani M, Lombardi F, Guzzetti S, et al. Powerspectral analysis of heart rate and arterial pressure variabilities as marker of sympathovagal interaction in man and conscious dog. Circ Res 1986;59:178-93.

19 Pomeranz B, Macaulay RJB, Caudill MA, et al. Assessment of autonomic function in humans by heart rate spectral analysis. Am f Physiol 1985;248(Heart Circ Physiol 17): H151-3.

20 Jaffe RS, Fung DL, Behrman KH. Optimal frequency ranges for extracting information on autonomic activity from the heart rate spectrogram. I Autonom Nerv Syst 1993;46:37-46.

21 Yaragani VK, Srinivasan K, Vempani S, et al. Fractal dimension of heart rate time series: an effective measure of autonomic function. F Appl Physiol 1993;75:2429-38.

22 Bigger JT, Fleiss JL, Steinman AB, et al. Frequency domain measures of heart period variability and mortality after myocardial infarction. Circulation 1992;85:164-71.

23 Rizzoni D, Castellano M, Beschi M, et al. Plasma norepinephrine and spectral analysis of the heart rate during cardiopulmonary receptor stimulation in normal and hypertensive subjects. F Hypertens 1991;9(suppl 6):S84-5.

24 Koizumi K, Terui N, Kollai M. Effect of cardiac vagal and sympathetic nerve activity on heart rate in rhythmic regulation. F Auton Nerv Syst 1985;248:H151-3.

25 Bernardi L, Leuzzi S, Radaelli A, et al. Low-frequency spontaneous fluctuations of R-R interval and blood pressure in conscious humans: a baroreceptor or central phenomenon? Clin Sci 1994:87:649-54.

26 Vila J, Palacios F, Presedo J, et al. Time-frequency analysis of heart-rate variability. IEEE Eng Med Biol Mag 1997;16: 119-26.

27 Task Force of the European Society of Cardiology and the North American Society of Pacing and Electrophysiology. Circulation 1996;93:1043-65.

28 Maseri A. Pathogenetic mechanism of coronary artery spasm. f Am Coll Cardiol 1989;14:610-12.

29 Yasue H, Touyama M, Kato H, et al. Prinzmetal's variant form of angina as manifestation of alpha-adrenergic receptor-mediated coronary artery spasm: documentation by coronary angiography. Am Heart $\mathcal{f} 1976 ; 91: 148-55$.

30 Crea F, Chierchia S, Kaski JC, et al. Dopamine-induced coronary spasm. Circulation 1985;72(suppl III):III-415.

31 Specchia G, De Servi S, Falcone C, et al. Coronary arterial spasm as a cause of exercise-induced ST-segment elevation in patients with variant angina. Circulation 1979;59.94854 .

32 Chierchia S, Davies G, Berkemboom G, et al. Alphaadrenergic receptors and coronary spasm: an elusive link. Circulation 1984;69:8-14.

33 Robertson RM, Bernard Y, Robertson D. Atrial and coronary sinus catecholamines in the course of spontaneous coronary artery spasm. Am Heart f 1983;105:901-6.

34 Waters D, Miller D, Boucard A, et al. Circadian variation in variant angina. Am f Cardiol 1984;54:61-4.

35 Nademanee K, Intarachot V, Josephson MA, et al. Circadian variation in occurrence of transient overt and silent myocardial ischemia in chronic stable angina and comparison with Prinzmetal's angina in men. Am 7 Cardiol 1987;60:494-8.

36 Endo M, Hirosawa K, Kaneko N, et al. Prinzmetal's variant angina: coronary arteriogram and left ventriculogram during angina attack induced by methacholine. $N$ Engl f Med 1976;294:250-7.

37 Furchgott RF, Zawadzki JV. The obligatory role of endothelial cells in the relaxation of arterial smooth muscle by acetylcholine. Nature 1980;288:373-6.

38 Nowlin JB, Troyer WG, Collins WS, et al. The association of nocturnal angina pectoris with dreaming. Ann Intern Med 1965;63:1040-6.

39 Somers VK, Dyken ME, Mark AL, et al. Sympathetic-nerve activity during sleep in normal subjects. $N$ Engl f Med 1993;328:303-7.

40 King MJ, Zir LM, Kaltman AJ, et al. Variant angina associated with angiographically demonstrated coronary artery spasm and REM sleep. Am f Med Sci 1973;265:419-22.

41 Airaksinen KEJ, Ikaheimo MJ, Huikuri HV, et al. Responses of heart rate variability to coronary occlusion during coronary angioplasty. Am f Cardiol 1993;72:1026-30.

42 Luria MH, Sapoznikov D, Golon D, et al. Early heart rate variability alterations after acute myocardial infarction. $A m$ Heart 7 1993;125:676-81. 